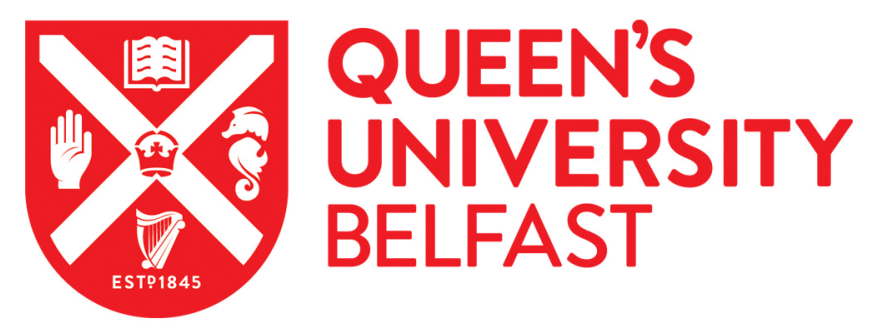

\title{
The Impact of the Recent Economic Recession on the operation of the NEC Contract in Northern Ireland
}

Brooks, T., Spillane, J., Tansey, P., \& Hendron, C. (2016). The Impact of the Recent Economic Recession on the operation of the NEC Contract in Northern Ireland. Construction Management Economics, 34(6), 393-417. https://doi.org/10.1080/01446193.2016.1194522

\section{Published in:}

Construction Management Economics

\section{Document Version:}

Peer reviewed version

Queen's University Belfast - Research Portal:

Link to publication record in Queen's University Belfast Research Portal

\section{Publisher rights}

(c) 2016 Informa UK Limited, trading as Taylor \& Francis Group.

This is an Accepted Manuscript of an article published by Taylor \& Francis in Construction Management and Economics on 10 June 2016, available online: http://www.tandfonline.com/10.1080/01446193.2016.1194522.

\section{General rights}

Copyright for the publications made accessible via the Queen's University Belfast Research Portal is retained by the author(s) and / or other copyright owners and it is a condition of accessing these publications that users recognise and abide by the legal requirements associated with these rights.

Take down policy

The Research Portal is Queen's institutional repository that provides access to Queen's research output. Every effort has been made to ensure that content in the Research Portal does not infringe any person's rights, or applicable UK laws. If you discover content in the Research Portal that you believe breaches copyright or violates any law, please contact openaccess@qub.ac.uk. 


\title{
The impact of the Recent Economic Recession on the
}

\section{operation of the NEC Contract in Northern Ireland}

\author{
Abstract:
}

In May 2006, the NEC contract was introduced as the preferred contract for Northern Ireland public sector works. This was subsequently followed by the 2007 economic crash and ensuing recession, which continues to affect the Northern Ireland Construction Industry, to a greater extent than the remainder of the United Kingdom (UK). However, use of the NEC contract has increased during this period, particularly in the public sector. There has been debate in the literature regarding the impact of the NEC contract on adversarial behaviour, but little consideration of the impact of external economic factors on the use of the NEC contract. Using a sequential mixed method approach, the study aims to fill this gap in knowledge, through examination of the impact the economic downturn has had on the operation of the NEC contract in Northern Ireland. Qualitative and quantitative findings show that the demands placed by the NEC contract, and the effects of the economic recession, have exerted opposing forces contract implementation, thus hindering its execution. The findings can lead to a deeper understanding, in the context of both industry and academia, of situations where a lack of resources may negatively impact the operation of the NEC contract.

Keywords: Contract Administration, Contractual Relations, Northern Ireland, Recession. 


\section{Introduction}

The New Engineering Contract, or The NEC Contract as it is more commonly referred to, was first launched in 1993. Its purpose is to improve the efficiency and value delivered by the construction industry, in conjunction with a reduction in disputes, by requiring contemporaneous agreement of change and promoting a culture of openness, trust and cooperation (Eggleston, 2006). When the construction industry is in a period of strong growth, it can be difficult to align the needs of contractors and clients (Kadefors, 2004) or architects and contractors (Ankrah and Langford, 2005), as their desired project outcomes can differ widely. However, adversarial behaviour can be stimulated by the pressures of operating during periods of economic decline, when profits and resources are at a low ebb, resulting in businesses having to fight for survival (Williamson, 1975).

In May 2006, when the public sector announced the NEC contract as its preferred contract of choice, Northern Ireland was experiencing a period of rapid and prolonged economic growth (Verick and Islam, 2010). However, North American subprime mortgage market problems began to emerge shortly afterwards, with a subsequent collapse in 2007. This led to the worst global recession since the Great Depression of the 1930s (Verick and Islam, 2010; Tansey and Spillane, 2014). Eadie et al. (2013) together with Tansey et al. (2014) outline that the Northern Ireland construction industry has been deeply affected by this recession, suffering a sharp downturn in employment and productivity levels. The prolonged effects of the recession are starting to ebb, but recent industry statistics show that its consequences linger to this day in Northern Ireland (DFPNI, 2014).

Research on the NEC contract to date has included its introduction and implementation, and its impact on trust and cooperation. In 1997, John Broome tested the early experiences of 
NEC contract users through 81 semi structured interviews. Amongst his findings were that the NEC contract was likely to expose shortcomings in its users, and that increased resourcing was required to deal with contract administration during its use; however, this additional input during the contract led to more efficient contract administration and greater cooperation amongst project participants (Broome, 1997). Hughes and Maeda (2002) in their wider study of procurement practice, statistically analysed 187 questionnaire responses. The respondents were largely sceptical regarding the spirit of trust and mutual cooperation mandated in the NEC contract, suggesting it was difficult to enforce, finding 'win win' contracts impractical and indicating that imprecise contracts may encourage opportunism. Most respondents felt that flexibility of contract terms would be exploited by the contracting parties, querying the flexible, 'one size fits all’ approach of the NEC contract. The requirement to act in a spirit of trust and mutual cooperation has generated much debate: Minogue (2013) and Bingham (2013) have written polemical pieces respectively pro and anti such 'good faith’ contract clauses.

In 2013, in the experience of several questionnaire respondents, the reduction in tendering opportunities in Northern Ireland had led to an increase in procurement challenges (Eadie et al., 2013). Challender et al., (2014) concluded that the recent recession could be undermining trust, and Tansey et al., (2013) found through case study research that cost reduction and restructuring featured prominently in the subject companies' response to the recession.

From the extant research, it can be inferred that the NEC contract, with opinion divided over its exhortation to work in a spirit of trust and mutual cooperation, and its resource intensive requirements for proactive contract administration, might be more vulnerable to the impact of the recession than other, more traditional forms of contract. The impact of the recession on the NEC contract has not been explicitly studied, with the exception of Brooks and Spillane 
(2015), which this study develops. This paper aims to further fill this gap in knowledge, through the development and verification of the earlier research, and testing of the hypothesis generated from existing research, by means of the inclusion of quantitative survey results, subsequent analysis and discussion. This study therefore aims to examine the introduction of the NEC contract in Northern Ireland during the period 2010 to 2014, in the context of the adverse prevailing economic conditions.

Initially, the development of the NEC contract and its impact on trust and collaboration is explored. The events leading up to the recent economic recession and the impact of the recession in Northern Ireland are reviewed. The next section explains the methodology and research method. The qualitative results are analysed and discussed, followed by description and analysis of the quantitative results. The final section entails conclusions and recommendations for further research.

The findings of the study can therefore lead to a deeper understanding, in the context of both industry and academia, of how a reduction in resources negatively impacts the operation of the NEC contract. The critical realist stance applied entails that the research should be generalised within the social context of the study. However, the NEC contract has been widely used internationally, and the impact of the recent economic recession has been felt across the globe. Hence the findings of this study will be of interest to international readers. 


\section{Research Aim}

Through review of extant literature, a hypothesis is developed. The hypothesis is then tested through examination of two main factors: firstly, the impact of the recession on businesses, resourcing, trust and cooperation. Secondly, experiences and perception of the NEC contract. The study will investigate these two elements, to ascertain the extent the negative impact of the recession has had on its operation and use. In accordance with critical realist approach adopted, a key objective is to suggest practical action which may guide others towards a more successful application of the NEC contract during times of economic instability.

\section{Review of Literature}

\section{The NEC Contract}

The aims of the first NEC contract were threefold: the contents to be presented with clarity and simplicity, to have flexibility of use, and to act as a stimulus to good project management (Gerrard, 2005). In 1994, in response to the recommendations of the Latham report, a "specific duty for all parties to deal fairly with each other...in an atmosphere of mutual cooperation" (Latham, 1994, p.37) was included in the second edition of the contract. Studies which were undertaken in the years following the NEC contract's publication confirmed that it did foster greater cooperation and was considered easy to use. Broome and Hayes concluded in 1997 that, whilst the contract's aim for clarity and simplicity of language was not entirely met, it was clearer and easier to use than other forms of contract. Broome undertook qualitative analysis of 81 interviews, (1997) citing interviewees’ comments of a 'feeling' of greater cooperation and openness as one of the contracts benefits. However, this anecdotal data taken from selected quotes is not quantified. In 2000, Thompson et al., from 
their review of existing literature, stated that the improved communication engendered by the contract had led, at least in part, to the complete absence of litigation on any construction project using the NEC contract between 1993 and 1997. This early research publicised the contract's successes and encouraged its early adopters. However, praise for the contract was not universal. Hughes and Maeda (2002) questioned the practicality of win-win contracts and suggested that a reliance on trust introduced ambiguity into the contract. This 'ambiguity' was also treated with suspicion by members of the law profession (Eggleston, 2006). Rooke and Seymour (1995) explored resistance to the contract, citing conservatism, reaction from lawyers and a 'claims culture' within the industry, as potential sources of resistance. More recently, Paul Blackburn, as quoted in Stimpson (2011), discusses problems with the Cambridge Guided Busway project and argues that contract choice should be project specific. Doherty's article (2012) suggests that NEC project failure, when it occurs, tends to be on a large scale. Doherty (2012) concurs with EC Harris' (2013) analysis, that common factors leading to contract failure include: failure to provide adequate resources to properly administer the contract, departure from contract procedures, and a lack of understanding of the contract. Interestingly, Rudi Klein (2015), NEC users’ group president and a prominent contract advocate, agrees that NEC contract failure tends to be due to people not operating the contract as it was intended, (for instance through misuse of ' $z$ ' clauses), rather than the contract itself.

\section{Trust and cooperation}

The contract requirement to work in a spirit of 'mutual trust and cooperation' has been the subject of much debate. Both Bingham (2012) and Minogue (2013) suggest in their articles that it is unenforceable - Bingham (2012, p1) memorably parodies 'good faith clauses' as “this tree-hugging good faith thingamajig.” Mason (2008, p4) outlines that it was only ever 
intended to "influence, rather than mandate.” Kadefors (2004) developed a theory of trust in interorganisational relations using previous primary case study research and analysis of literature, finding trust is a prerequisite for constructive cooperation. Smyth et al, (2010), through examination of theories of trust and analysis of existing publicly available quantitative and qualitative data, propose that trust is socially constructed. They find that it is developed iteratively throughout a project, that it builds confidence and financial value, and that the subsequent perception of customers of an improvement in service contributes to a firm’s embedded social capital. Nicollini (2002) suggests from qualitative analysis of literature, group and individual interviews, that good 'chemistry' can bring project participants together, reduce conflict, increase morale and mutual understanding, and positively affect project outcomes. It is this good 'chemistry' which can be used to describe the relational and social issues surrounding the management of a contract, that the requirement 'to act in a spirit of trust and mutual cooperation' is trying to encourage.

'Trust' holds different meanings for different groups of people, it depends on the attitude of key project participants (Pinto et al, 2008) and is difficult to build during short duration, oneoff projects (Bresnen and Marshall, 1998). Pinto et al., (2008) built on the theoretical framework of Rousseau et al (1998) and Mayer et al (1995) to divide trust into three distinct categories: integrity trust (will the other party be opportunistic and exploitative?), competence trust (does the other party have the ability to fulfil his obligations?) and intuitive trust (which has also been described as a 'gut feeling'). Khalfan et al. (2007) analysed 40 interviews across 5 case study projects to find that adversarial behaviour tends to increase and trust to decrease in times of economic difficulty. In addition, they suggest that mistrust and suspicion often result when the contract price does not fairly relate to the extent of work to be completed. Manu et al. (2012) explored extant literature on trust in construction in the 
context of the recent recession and suggest that integrity trust diminishes when companies are fighting for survival in harsh economic conditions. The condition of vulnerability engendered by a precarious economic situation (Rousseau et al., 1998) reduces trust; where project participants will attempt to minimise risk (Loosemore 1988) and adopt adversarial, game playing behaviour (Bresen and Marshall, 1998). Smyth et al. (2010, p120) find that individual performance is affected by "prolonged conditions of insecurity and fear.” Examining society wide phenomena, Tang and Koveos (2008, p1046) use GDP figures and existing research to propose that the cultural values of "individualism, power distance and long term orientation” are related to national Gross Domestic Product (GDP) per capita. These studies confirm Latham's 1994 proposition that "It is not easy to create teamwork in construction when everyone is struggling to avoid losses" (Latham, 1994, p9).

\section{The Economic Recession}

The NEC3 contract was first used as the public sector preferred contract in Northern Ireland in 2006, at a time when Northern Ireland was experiencing a period of sustained economic growth. Few economists predicted what was to follow. Pre-2007, the belief persisted amongst economists that the economy was inherently stable (Krugman, 2009). Financial losses in the United States subprime market in 2007 spread quickly to impact the UK financial sector. The run on the Northern Rock bank in September 2007 ended only when the Bank of England gave emergency financial support, by guaranteeing the bank’s deposits. Lehman Brothers collapsed in 2008, described by Stock and Watson (2012, p2), as a "new and unprecedented failure...of the financial plumbing”. Banks became risk averse and interbank lending dried up (Hall, 2011). The financial collapse was to spread globally and send shockwaves around the world, leading to the deepest economic recession in six decades (Verick and Islam, 2010). 
As turmoil engulfed the financial system, confidence drained from the construction industry. Statistics released by the Office for National Statistics for Northern Ireland (DFPNI, 2014) clearly demonstrate a peak in construction output in 2007, followed by a steady downward trajectory in output from 2007 to 2014. The output in late 2014 was $45.3 \%$ lower than that recorded at its peak in 2007, while construction employment in 2013 was 37\% below its 2007 peak. Output figures also demonstrate that Northern Ireland's construction output fell further, and has taken longer to recover from the recession, relative to the rest of Great Britain. Moreover, in 2014, Great Britain’s construction output was 99\% of its average 2011 output figure, compared with just 86\%, in the context of Northern Ireland (DFPNI, 2014).

Tansey et al., (2013) find that construction companies in the UK and Ireland responded to the recession with a pursuit of cost leadership strategies, reducing costs as a survival mechanism. Late Payments impacted on cash flow, exacerbating financial stress (Dancaster 2008). In 2010, Lowe and Moroke found construction insolvency rates were still rising, demonstrating the trend where insolvency lags behind economic recovery. They also state that the failure rate for construction was twice that of other industries during previous recessions (Low and Moroke, 2010).

Market decisions are made by people; hence they act imperfectly in times of economic turmoil (Buchanan, 2001). Tendering decisions are based on approximate information due to bounded rationality and information impactedness (Simon, 1972). This unpredictability, together with the limits of bounded rationality, combine to generate the conditions where game playing and opportunism become the norm (Williamson, 1975). "Self-interest seeking with guile" (Williamson, 1975, p9) increases as generosity, and giving the benefit of doubt to another party, becomes an expensive luxury. Opportunism is described by Cousins et al. (2008, p31) as "achieving one's goals through calculated efforts of guile, lying, stealing, 
cheating, passing false information, distorting or disguising information and generally misleading the other party". Although much of this behaviour is legal, it is constrained by fear of potential reputational damage.

Rivalry between competitors intensifies during periods of low or no economic growth, with a number of players fighting over a piece of the ever shrinking pie (Porter, 1980), leading to long term value and income suppression. Price cuts are necessary to survive; however, when price cuts by one company are replicated by its competitors, this leads to a 'race to the bottom'. Construction as an industry has high exit barriers - reputation, asset disposition, loyalty to a workforce, history, and emotional attachment to family businesses (Zeng et al., 2005; Kang, 2006). This leads competitors to continue to trade long after a dispassionate hardnosed commercial advisor might recommend doing so, further supressing long term value across the industry (Porter, 1980).

Themes identified from the literature have been combined to form the three sections of the hypothesis for this study. Firstly, trust is fragile and difficult to build (Smyth et al., 2010) and cannot be created through a clause a contract (Bingham, 2012). Second, the recent economic contraction has decreased available resources (Tansey et al., 2014) and increased vulnerability (Lowe and Moroke, 2010.) Third, that opportunism and game playing has increased during the recession (Williamson,1975). Hence the hypothesis that the recession has decreased trust and cooperation, and decreased available project resource, which in turn has negatively impacted on the operation of the NEC contract, is developed. 


\section{Methodology}

Use of mixed methods entails rejection of the incompatibility thesis, which states that use of specific research methods (qualitative and quantitative) which emanate from distinct, opposing abstract research paradigms (interpretivist and positivism), creates an inherent contradiction and hence is unsupportable (Howe, 1998; Kuhn, 1996). Dainty (2007) calls for courage to challenge entrenched views but warns that if not considered carefully, this course of action could lead to a “methodological no man’s land” P8. Some mixed methods researchers have adopted an a-paradigmatic stance (Tashakkori and Teddlie, 2003), however simply ignoring the issue is not a satisfactory solution to the problem which Lipscomb (2011) describes as a 'Gordian knot', as no research is paradigm free.

The Pragmatic approach is built on the works of Pierce, James and Dewey (Lipscomb, 2011). It entails selecting the most appropriate conceptual and research tool on the basis of 'what works' to answer a particular question. Proponents of pragmatism argue that the boundaries between paradigms are arbitrarily set by competing factions of the research community. The characteristics of each group's views of the nature of reality, truth and knowledge are exaggerated by the opposing group in order to discredit them, and are characterized based on social and political values (Morgan, 2007). Pragmatists hold that nuances of the research process lead to a continuum of interpretativism and positivistism. Permeable paradigm boundaries (as suggested by Guba and Lincoln, 2005) undermine their alleged absolute internal consistency and dilute the rigid incommensurability argument. Pragmatists argue that research paradigms can 'peacefully coexist' (Johnston et al 2007). They question the connection between methodological constraints and the research methods used, calling for more flexibility (Johnston et al, 2007). Some pragmatists argue that research paradigms should not be viewed as constraints, rather as lenses to focus research and debate. They call 
for a dialogue between paradigms in order to generate a greater depth of understanding. Opponents argue that this approach opens debate, however they find that pragmatists still do not satisfactorily resolve the philosophical contradictions inherent in the incompatibility of the methods used.

This research takes the stance of critical realism, which provides a solid philosophical foundation for the study of phenomena at different levels combining a number of theoretical perspectives. It avows that a real world exists beyond our own perceptions and thoughts (a realist ontology). It also holds that our understanding of this world is a product of our own mental constructs, that it is not possibly to perfectly understand the world (a constructivist epistemology), recognizing the value of an interpretative perspective (Bhaskar, 2008). By holding these two doctrines simultaneously, it offers a third way between positivist and interpretivist standpoints (Maxwell and Mittipalli 2010). It is not always possible to observe the real world directly, however we can infer causal mechanisms which underpin the interaction of people and their environment from observations using abductive reasoning (Bhaskar 2008). In common with pragmatism, critical realists are concerned with generating theories which 'work’ and their 'practical adequacy’ (Johnston and Duberley, 2000).

In accordance with this critical realist epistemological and ontological standpoint, it must be acknowledged that the researcher's internal, embedded values and perspectives have inevitably had an impact on the conduct and outcome of the research itself. Critical realism holds that our view of the world is conditioned by experiences and assumptions. The researcher's experience working as an architect and as bid manager for a medium sized building contractor will influence the research, if only at a subconscious level, despite best efforts to avoid prejudice or preconception. The researcher's previous experience, both of the recession and of the NEC contract, indicated that this might be an interesting topic to explore, 
whilst at the same time highlighting possible pre-existing assumptions. The relationships developed with interview subjects must impact on the interview itself and analysis of the same, despite efforts to maintain neutrality.

\section{Research Method}

This study uses sequential mixed methods with the qualitative study feeding into the development of the quantitative. The qualitative analysis (of semi-structured, individual interviews) is followed by a quantitative approach (using an industry circulated questionnaire survey) and subsequent analysis (data reduction and sample t-tests). Equal weight is given to each method - hence it could be described as a ‘true' mixed methods study (Johnston et al, 2007). It rejects the view that one form or other must be dominant to accommodate epistemological and ontological concurrence, adopting a critical realist stance. This approach confirms that it is possible, in fact desirable, to explore and understand a variety of understandings and experiences of a phenomenon, at the same time it is equally important to measure, scale and quantify the effects of the same phenomenon (Maxwell and Mittapalli, 2010).

Bergman (2008) finds that the distinction between qualitative and quantitative methods has been overstated. That the existence of mental states impacts on the relationship between cause and effect is an important part of critical realism's approach to quantitative study (Maxwell and Mittapalli, 2010). This aligns with Sayer's stance (1992) that critical realists view causal relationships through the lens of the social relationships and objects which are the foundations for the causal mechanisms. The critical realist approach considers the social context part of the causal mechanism. (Maxwell, 2008) This differs from an interpretative viewpoint in that the social mechanisms are considered part of reality, not abstractions or 
constructs (Maxwell and Mittapalli, 2010). This approach does limit the generalizability of the study to the social context in which it is undertaken. However, as noted before the financial and resourcing issues generated by the recession on one hand, and the demands placed by the NEC contract on the other, are not limited to this context. Further research is therefore required to confirm whether the conclusions derived can apply to the wider context of the UK.

This study uses triangulation of methods in an attempt to counter the partiality and fallibility of individual research methods and build up a picture of the underlying social mechanisms behind the subject from a number of perspectives (Dainty, 2007). The qualitative method helps to underline the social context of the issued examined, and helps to overcome the limitations of the variable focused questionnaire. The questionnaire can provide a more complex and diverse picture than that given by the qualitative analysis alone (Abowitz and Toole 2010).

The initial exploratory qualitative approach permits further examination of the research aims and theory generated from the literature review. This is undertaken through discussions with practitioners, who have first-hand experience of the topic. As Cresswell (2003) states, this approach facilitates the respondents' understanding of their experience, enabling them to give a detailed account of their experiences in their natural context, generating rich, deep data and permitting the exploration of complex factors. It helps to explain how the respondents have been effected by the recession, how they and their organisations have reacted and more importantly, why.

The interview approach adopted in this instance is semi-structured, balancing the need to ensure focussed coverage of core questions with each respondent, with the ability to probe 
further the respondents' answers and experiences, where appropriate. The interviews were conducted between November 2013 and April 2014, each lasting between 40 and 60 minutes. The questions are themed into areas covering the respondents' experience of the implementation of the NEC contract, their experience of the recession, its impact on resourcing levels and competition. The sampling strategy for the interviewees is based on a two tiered selection process of convenience and subsequent criteria. Using samples of convenience overcomes low response rates in applied settings, and allows subgroups of interest to be included (Abowitz and Toole, 2010). Criteria include individuals who have 10 years or more of experience in their chosen field and are familiar with the NEC contract. The interviewees must have personal experience of the recent economic recession and have firsthand knowledge regarding how the recession has affected their organisation. The interviewees chosen are firstly, an Architect of 12 years’ post chartered experience who has experience of the NEC short form of contract. Secondly, a Structural Engineer with 40 years' post qualification experience, who has been company director of a Structural and civil engineering consultancy for 15 years. Thirdly, a Contracts Manager with 36 years’ experience in construction, 31 as a contract manager with projects from $£ 18 m$ to $£ 50,000$ in value including NEC option A and B contract. The Client, who formerly worked as Bid Manager for a large contractor, has 20 years’ project management experience and in depth knowledge of the NEC contract. The Construction Adjudicator / Arbitrator's background is in Quantity Surveying, and has worked as an adjudicator and arbitrator for 16 years, dealing with all types of contract including NEC. Finally, the senior representative of the Construction Employers Federation (CEF). The CEF acts as a representative body for over $70 \%$ of contractors and subcontractors in Northern Ireland. The senior representative's job role involves engagement with industry, giving him a very good 'overview' of issues affecting construction in Northern Ireland. This sample of convenience covers a broad 
spectrum of the construction industry in Northern Ireland and is formulated in an attempt to probe the issues under consideration from differing perspectives. Interviews are recorded using both audio recording in conjunction with shorthand note taking. Subsequently, each interview is transcribed verbatim, directly after the interview; thus providing the opportunity for the interviewer to seek clarification from the interviewee, should it be required.

Subsequently analysis of the transcribed text is undertaken using nVivo $10^{\mathrm{TM}}$ qualitative analysis software. This software enables complex text to be examined in detail, with themes and 'nodes' identified and graphically represented. It also enables detailed in-text analysis and themes to be grouped and examined in further detail, without reliance on memory. Prior to undertaking a detailed analysis of the text, a word frequency query is carried out, to identify commonly occurring words. This provides a dispassionate analysis of the text and serves as a useful mechanism to ensure that key words and themes are not omitted. Following initial analysis of the transcripts and examination of the word frequency results, a number of themes arising are identified, which form the basis of the coding. The coding process is repeated for each interview, in an attempt to achieve coding ‘saturation' and fully mine the richness of textual information. Following theme identification, concepts are then grouped in parent / child relationships and linked, in order to identify causal or parallel relationships between categories and central themes. The information from all interviews is compared, using emerging topics from all interviews to justify identification of themes. The subsequent factors are then categorised and included in the following questionnaire survey for industry circulation.

Following analysis of the interview transcripts using Computer Assisted Qualitative Data Analysis Software (CADQDAS), coding and interpretation, a self-administered questionnaire survey is developed to explore the issues raised. The questions are formulated in order to 
further develop and test the hypothesis generated from the literature and the findings from the qualitative analysis, hence are developed from the literature and qualitative analysis as demonstrated in table 1 . The questionnaire is divided into six sections. The first explores the respondents' background using categorical variables. The remainder of the sections use a Likert scale of 1 to 5; where 1 is strongly disagree, 2 is disagree, 3 is neither agree nor disagree, 4 is agree, and 5 is strongly agree. The following sections probe respondents' experience of the NEC contract, including their views on the need for this contract. This includes their perception of the NEC contract, their training and understanding of the contract, and their views on the benefits and drawbacks of the contract. The final two sections include exploration of the impact of the 2007 / 2008 recession on the respondent and their organisation and the respondents' longer term predictions for use of the NEC contract.

Table 1. Factors, and their sources, for inclusion in the questionnaire survey.

Those who had not used the NEC contract are not excluded from participating in the study. The use of the NEC contract had only been widespread in Northern Ireland for seven years prior to the survey. Those who have no practical experience form a significant portion of the industry, whose opinion is still valid and worth including. In addition, the data gathered from those who have used the contract before is compared to those who have not, in order to examine the impact of its use on the responses. The questionnaire is piloted amongst three industry professionals, who give feedback regarding ease of use, consistency and clarity of the questions. Amendments are made to remove ambiguity thus identified. The elimination of ambiguity is crucial when using a self-administered questionnaire, as no one is present to explain or assist the respondent (Kumar, 2005). Of 254 questionnaires circulated, 103 responses were received, giving a response rate of $40.5 \%$. The total eligible population (all those working in the Northern Irish construction industry) is estimated to be 30,010 in 
Quarter 12014 (DFPNI, 2014). Thus the themes generated by the questionnaire are tested on a wider cross section of the industry, to assess if they are generalisable to apply to the entire Northern Ireland construction industry (Cresswell, 2003).

The first quantitative analysis technique applied is data reduction. This method of analysis enables the initial 37 factors measured on the Likert scale (excluding the 5 categorical variables) to be condensed into a more concise array of constructs, which have most impact on the data hence uncovering the most important underlying themes within. The analysis groups variables which correlate, suggesting that these variables describe the same underlying conditions or themes. Field (2009, p 628) summarises the purpose of using data reduction using factor analysis as the ability "to reduce a data set to a more manageable size while retaining as much of the original information as possible”.

In carrying out the process, data reduction is undertaken in three distinct steps (Oyedele and Tham, 2007). Firstly, the factors are tested for suitability of analysis using both the KMO (Kaiser - Meyer - Olkin) test and Bartlett's test of sphericity. The KMO test determines whether the size of the sample is sufficient to generate reliable statistical results. Bartlett's test of sphericity assesses the strength of the connections between variables, to ensure that they are neither too highly nor insufficiently correlated, to permit data reduction. Following this first test, factors are extracted, using the principal component method of extraction, where eigenvalues are generated for each discrete component. The eigenvalue and scree plot for each factor are then used to determine which should be retained and examined further, and which are superfluous (Acton and Miller, 2009). Finally, a varimax rotation of the retained factors is undertaken. This groups factors into components based on the loading which each component has on the underlying theme. 
To complement the data reduction, sample t-test analysis of the data is undertaken. This test compares the average scores of distinct groups, to determine whether there is a significant statistical difference in their responses to particular questions. The sample t-test assesses if the difference between the mean results of the two groups is statistically significant or merely a chance outcome.

A model is then developed as a way of visualising the explanation of the respondent's experiences to the qualitative and quantitative investigation and the themes arising within the social context.

\section{Qualitative Analysis and Results}

Each of the six interviews is digitally recorded and transcribed verbatim, to yield 28,404 words of information, all of which is analysed using nVivo ${ }^{\mathrm{TM}}$ version 10 . Full transcription of the interviews in conjunction with use of nVivo aids the capture of an accurate picture of the data and give transparency and rigour to the data analysis process. Emerging themes and relationships are developed, as the interviews are coded (sentences and phrases which represent a particular concept digitally highlighted) and sorted (similar coded sections of text are grouped). Key words, phrases, ideas, similarities and consistencies, both within and between each text, and those identified within the literature review, are used to identify themes. During the iterative coding process, care is taken to try to avoid bias and focus on the meaning intended by the participants. Coding stripes are visible in the margin of the text, making it possible to view coding use and progress towards coding saturation. Codes are related to one another, categories are refined and developed, with connections and links established through use of axial coding (Strauss and Corbin, 1998). 
Coding yields the two main categories of 'NEC Contracts' and 'Recession' with 13 subcategories and 16 further sub categories relating to the central themes as shown in figure 1; where subsequently, the key findings from the qualitative analysis are summarised.

Figure 1. Qualitative coding - 'NEC Contract' and 'Recession' Categories and subcategories

\section{The NEC Contract:}

\section{Experience of the NEC Contract}

Whilst the reception of the contract is generally positive, concurring with Broome (1997) and Broome and Hayes (1997) this is not universal, demonstrating the inherent conservatism observed by Rooke and Seymour (1995). The adjudicator calls the contract “an engineer's conceit," whereas the architect characterises it as unwieldy when dealing with the complexities of construction - as a contract better suited "for painting lampposts". The CEF representative calls for a pragmatic assessment of the contract. He states that the time for argument over whether it should be used has passed, that it is being widely used and that contractors and consultants should 'get on board.' He praises the clarity and certainty that the use of a single form of contract throughout the public sector brings to the industry. Conversely, the arbitrator describes in negative terms the way that some projects are inappropriately 'shoehorned’ into the contract, endorsing Blackburn's assertion (Stimpson, 2011) that contract choice should be project specific. This, combined with Hughes and Maeda’s findings (2002) question the ‘one size fits all' adoption of the NEC contract. The dichotomy of views expressed by both respondents and academics suggests that the case for the use of a universal contract is far from settled. 


\section{New contract, lack of understanding}

Although the NEC contract has been in operation in the UK for some time, the interviewees still consider it a 'new' contract in Northern Ireland. The CEF representative describes the process of absorbing this new contract as a race between contractors and consultants, the prize being a commercial advantage over the other group. In the experience of the interviewees, this race is being won by contractors - they describe a small but significant group of consultants and clients who have little training and knowledge of the contract and who do not operate it as it was intended. The client claims that some consultants are "abusing their role and their authority... the consultants then aren’t on top of it.” Lack of training and understanding of the contract is spreading uncertainty and mistrust. The Contracts Manager decribes a project using the NEC contract which made no reference to NEC clauses and procedures, in fact was run entirely as a JCT contract, because the consultants didn't understand how to run an NEC contract. Klein (2015), EC Harris (2013) and Doherty (2012), all agree that NEC contract breakdown is largely due to failure to properly operate the contract and deviation from its procedures. This danger is dissipating, as use of the contract becomes more widespread and knowledge of its procedures embedded (Gould, 2015). However, it does provide a clear indication that more training in the use of the contract, particularly for consultants, is needed.

\section{Stimulus to good project management, more onerous contract administration}

There is broad agreement amongst the interviewees that the contract does deliver on its original aim; that is, to stimulate good project management (as asserted by Broome, 1997; Broome and Hayes, 1997, and Gerrard, 2005). However, this comes at the expense of more paperwork and an increase in contract administration. Regular programme updates and the 
submission and assessment of Early Warnings and Compensation Events in particular, are cited as generators of additional paperwork, in comparison to other contracts. However, the benefits brought by these procedures in terms of clarity and contemporary resolution of problems are acknowledged. The CEF representative cites the strict adherence to timescales required by the contracts, as an advantage to contractors, as they confer new responsibilities on clients and consultants, which may be open to exploitation. The architect finds the contract 'admin intensive' and “unforgiving for the architect and unforgiving to the contractor.” The architect does find responding to spurious early warnings and compensation events generated by unscrupulous contractors who were attempting to break even on unprofitable contracts - takes up a large proportion of his time for no additional fee. It is inevitable that improved project management, the most important aspect of the contract according to Gerrard (2005), involves more intense contract administration as found by the interviewees.

\section{Trust and Cooperation}

The impact of the contract on trust and cooperation within the project team is viewed cynically by all interviewees, echoing the views of Bingham (2013). The arbitrator describes this clause as 'absolute drivel.' The contracts manager says that it is "nice words but it means nothing. Means nothing at all” and that some people "want...to be confrontational all the time; well there's not much you can do about that.” These views correspond with Smyth et al (2010) who conclude that trust is developed as a project progresses, inferring that the process of trust building can’t be engendered by a contract clause alone. Pinto et al (2008) find that trusting relationships depended on the attitude and perception of the parties concerned. The CEF representative, contracts manager, arbitrator, architect and public sector client concur that the generation of trust in a project team depends much more on the personalities of those in the project team than the contract used. 


\section{The Recent Economic Recession}

\section{Experience of the Recession}

All of the respondents have suffered in some way due to the recession, in line with the findings by Tansey and Spillane, (2014), Eadie et al., (2013), and Tansey et al., (2014). The client says "when the market gets tighter and tighter and clients have the whip hand ...and they know they can squeeze the price down and that's all they're interested in"; although the arbitrator finds that clients ultimately suffer from unsustainably low prices. The CEF representative describes the submission of at or below cost tenders, as 'industrial suicide.' A bid by Northern Ireland's Central Procurement Directorate (CPD) to exclude abnormally low tenders was challenged in several court cases and the wording of this policy was subsequently watered down in 2015. This outcome is not a surprise to the arbitrator who describes the Northern Irish construction industry as "leading the way" in public sector procurement challenges. At the time of the study, the cumulative effect of many years of recession was showing amongst all respondents. Capital reserves were nearing exhaustion for several respondents' firms who were fighting for survival.

\section{Reduction in income, resources and staff - consultants}

The structural engineer reports that his business is being kept afloat through projects undertaken in the UK and Africa. His staff have been reduced from 17 to 6 , and he has been forced to axe his whole civil engineering department. His fees have been reduced by $30 \%$ since the peak of the boom. The architect reports that the fees in his sector (social housing) are squeezed, while at the same time, clients are introducing new contractual requirements including stringent environmental standards and the use of the NEC contract. These 
historically low fees force consultants to cut corners on projects; as remarked by the arbitrator who states that "if consultants were to do the job properly they'd not be competitive - they'd never win the job.”

The fees in education projects in particular are said to be at unsustainably low levels, with the consultant team fee for a recent large school project reportedly as low as $2.5 \%$. Competition for work is intensified by the large number of small consultant businesses which have been set up by those made redundant. These new businesses have very low overheads and further drive down consultant fees. This trend confirms Porters theory (1980), that the competition experienced during a period of low or negative economic growth will intensify and lead to reduced fees and long term suppression of income.

\section{Reduction in income, resources and staff - contractors}

The demise of many high profile, long standing Northern Irish contractors, demonstrates that it is not only consultants who have been suffering due to the recession. The CEF representative describes the loss of members who have held on through several years of the downturn, who had to go bankrupt, when they finally exhausted their capital reserves.

Late payment, from the client right down through the supply chain is rife. Fair and prompt payment charters have made little difference when public sector clients, supposedly champions of good practice, are themselves paying contractors late. As the client describes "prices are at an all-time low, profit margins are non-existent." 


\section{Contractors using any means to maximise profit as a survival tactic}

Williamson (1975) suggests that contracting industries with diminishing profits create an environment in which exploitation and opportunism flourishes. The respondents concur: when contractors are submitting at or below cost tenders, they are forced into maximising the income they make from every job. This also applies to contractors who previously allowed 'give and take' in a contract, in the interest of fostering long term contractual relationships. Integrity trust diminishes (Manu et al 2010) and short term survival tactics take over from investment in longer term social capital (Smyth et al, 2010). Contractors are taking advantage of gaps in tender packages, left by consultants who have cut corners when assembling tender documentation. These omissions are due in part to the consultants' reduced fee levels and staff numbers. Subcontractors are also being treated poorly, paid late and not always the agreed figure. As the public sector client puts it "the spirit of trust, of partnership is gone” because contractors are making profit "by any means that you possibly have, because it means the survival of your business.” The ability to accept a vulnerable position and open one's firm up to trust (Rousseau et al, 1998) is no longer an option. The arbitrator reports that this had led to an increase in disputes, confirming the findings of Khalfan et al. (2007) that trust will decrease, and Williamson's (1975) hypothesis that adversarial behaviour and opportunism will increase, in times of economic difficulty.

\section{Quantitative Analysis and Results}

Of the 103 respondents to the questionnaire survey, the vast majority are either Design Consultants (42\%) or Contractors (34\%). The remainder comprise Client/Developers (8\%) Quantity Surveyors (4\%) Project Management Consultants (9\%) and Other (4\%). Those who are classified as 'Other' include an Environmental Consultant, a Planning Consultant, an 
employee of a Government Built Heritage agency and an Architect. 71\% of the respondents have used the NEC contract prior to completion of the questionnaire. $50.4 \%$ of respondents work in an organisation of less than 50 people, the remainder work in larger organisations. $51.4 \%$ of respondents have 19 or less years' experience in the construction industry, the remainder have more experience. The subsequent information from the questionnaires is processed and analysed using factor analysis and independent sample t-tests, as discussed earlier.

Several questions directly tested elements of the hypothesis. The First element, that trust is fragile, difficult to build, and cannot be mandate in a contract, gave the following result:

Table 2. Quantitative testing of element 1 of the hypothesis

The Second element of the hypothesis, that economic contraction has decreased available resources and increased the vulnerability of organisations, gave the following result:

Table 3. Quantitative testing of element 2 of the hypothesis

The Third element of the hypothesis, that game playing and opportunism within the industry has increased, gave the following result:

Table 4. Quantitative testing of element 3 of the hypothesis

This 'raw' data appears to confirm the first three sections hypothesis. Further statistical analysis is used to determine underlying patterns in the data and differences between the responses of categories of respondent. 


\section{Data Reduction}

The KMO (Kaiser-Meyer-Olkin) test is used to determine whether the size of the sample is adequate to permit reliable statistical results. In order to conduct a factor analysis, the data, which needs to correlate "fairly well, but not perfectly" (Field, 2009, p. 657) is tested using Bartlett's test of sphericity and the KMO test.

Bartlett's test of sphericity tests the strength of the connections between variables - it checks that the data is sufficiently correlated to allow for analysis, whilst not being too highly correlated. The significance of the Bartlett's test should be $\leq 0.05$ - Bartlett's test of sphericity of 0.00 indicates that the variables are likely to have a correlation. All values on the anti-image correlation matrix are above 0.5 . This shows that there is a correlation between these variables and the others reported. The variables therefore satisfy the minimum standards required to undertake a factor analysis. The KMO figure of .709 sits within the range (0.7 - 0.8) described by Field (2009) as "good.”

Therefore both the KMO and Bartlett's test of sphericity indicated that factor analysis is appropriate and can proceed. Factors with eigenvalues greater than 1, which are also before the breaking point on the scree plot are retained. The preliminary factor analysis with varimax rotation reduces the data to two key components. Table 5 summarises these components and their associated factors.

Table 5. Rotated Component Matrix for Components 1 and 2

The rotated component matrix shows the relative importance of each variable and indicates which variables make up the leading components. The factor loadings are measured between 
\pm 1.0 . The factor loadings indicate the strength of the effect of a particular variable on a component, with positive values indicating a positive relationship and negative values showing a negative correlation. Factor loadings below \pm 0.5 have been supressed, as these are considered insignificant. This technique groups correlated variables, and unearths the underlying themes and relationships in the collected data.

Component 1, summarised as "The NEC contract stimulates Good Project Management" describes a positive reaction to the NEC contract. This component includes agreement that 'traditional' contracts aren't adequate and there is a need for an NEC type contract, that early warning and compensation event procedures are useful, and that use of the contract leads to fair risk apportionment between client and contractor. The negative loadings on factors 'the NEC contract is more complicated and time consuming to administer than other forms of contract' and 'The NEC3 contract is inflexible and unforgiving to consultants and contractors' represent a divergence with the interviewees’ responses, giving a more unqualified acceptance of the contract and its provisions. The remainder of this component reinforces the findings within the qualitative analysis of a broadly positive reception to the NEC contract.

Component 2 is summarised as "Negative Impact of the Recession on Project Resourcing". It describes the stretching of resources more thinly across projects and the converse expectation from clients that contractors and consultants should deliver a better service, for less income since the onset of the 2007 / 2008 recession. Again, this component confirms the outcome of the qualitative analysis, with regard to the effect of the recession on resourcing, combined with a more competitive environment and high client expectations. 


\section{Sample t-tests}

The Sample t-test compares the differences between the mean responses of two distinct groups of respondents, testing if the difference is statistically significant or merely a chance result. This technique allows the hypothesis to be tested against subgroups of respondent, to ascertain whether the responses vary according to the categories tested.

A Sample t-test is used to compare the mean answers given by Contractors and Design Consultants for all questions. For the purpose of this test, Client / Developers, Quantity Surveyors, and Project Management consultants are included in the category "Design Consultants.” Three statistically significant results are returned. In each of these answers, the Sig and Sig ( 2 tailed) results are $<0.05$. The responses to all other questions fail to show statistically significant differences $(\leq 0.05)$ between the two groups and are subsequently disregarded.

To demonstrate the meaning of these values, the first question is taken as an example ("I think that 'traditional' contracts, e.g. JCT, aren't adequate and there is a need for a collaborative type of contract like the NEC3"). Levene's test for equality of differences gives a Sig result of .038, disproving the assumption that there is no statistical difference in the results (with a confidence level of 96.2\%). The t-test sig 2 tailed result for equality of means of 0.001 shows that the means of the two groups (contractors and designers) are statistically significantly different.

Table 6. Sample t-test comparison of Design Consultants and Contractors’ responses 
This analysis illustrates that contractors are statistically $(\leq 0.05)$ more likely to believe that use of the NEC contract will lead to less conflict and formalised disputes in the construction industry than Design Consultants, with a difference between the mean answers of 0.64.

From the sample t-test, it emerges that Design Consultants are more likely than contractors to believe that their organisations’ income has reduced, since the onset of the 2007 / 2008 recession; with a difference between the mean answers of 0.76 . Contractors are more likely than Design Consultants to do whatever they can to gain additional income for their organisation within the bounds of the contract since the onset of the recession, with a difference between the mean answers of 0.86 . There is arguably more scope within the NEC contract for a contractor to claim additional money through the compensation event mechanism than for consultants. As referred to in the qualitative analysis, contractor claims generate more work for consultants for no additional fee; moreover this work is time bound, as the assessment of compensation events must be determined within time limits set by the contract, otherwise they are deemed accepted (Ennis, 2010).

A second Sample t-test is used to compare the mean answers given by those who work in organisations of 50 or more people, with those who work in smaller organisations for all questions. Three statistically significant results are returned. The responses to all other questions fail to show statistically significant differences $(\leq 0.05)$ between the two groups and are therefore disregarded. In each of the three retained answers, the Sig and Sig (2 tailed) results are $\leq 0.05$ (at least a 95\% confidence level). This means that in all three instances, Levene's test for equality of differences shows that the assumption that there is no difference in the results is unsupported. The t-test sig 2 tailed result for equality of means shows that the means of the two groups (those working in larger and smaller organisations) are statistically significantly different. 
Table 7. Sample t-test comparison of those working for larger and those working for smaller organisations

This illustrates that those working in larger organisations are statistically more likely to believe that Contractors in Northern Ireland have the skills, knowledge and understanding to fully implement the NEC3 contract than those working in smaller organisations, with a difference between the mean answers of 0.43 . This could be due to more management resources and formal training programmes present in larger organisations (Gould, 2015). Those working in larger organisations are more likely to believe that the use of the NEC contract will lead to fewer formal disputes than those working in smaller organisations, with a difference between the mean answers of 0.56 . The difference in the mean answers of 0.3 shows that those working in smaller organisations are more likely to have used the NEC contract before than those in larger organisations.

A final Sample t-test is used to compare the mean answers given by those who have 0 to 19 years' experience in the construction industry with those who have 20 or more years' experience. Two statistically significant results are returned. The responses to all other questions are omitted, as they do not show a statistically significant difference between the two groups. In both of the retained answers, the Sig and Sig (2 tailed) results are below 0.05 . This suggested that in all 3 cases, Levene's test for equality of differences shows that the assumption that there is no difference in the results is unsupported. The statistical significance between the mean responses of the two groups, (those with 0 to 19 years' experience and those with 20 or more years' experience), is confirmed by the t-test sig 2 tailed result for equality of means. 
Table 8. Sample t-test comparison of those with 20 or more years' experience with those with less than 20 years' experience

This shows that those with less experience are more likely than those with more experience to think that that there is a need for a non-traditional collaborative type of contract like the NEC with a difference between the mean answers of 0.77 . Those with more experience are more likely to believe that well informed, competent teams will work well together regards of the contract used than those people with less experience with a difference between the mean answers of 0.446 .

The results of the quantitative analysis can be summarised by the following diagram.

Figure 2. Quantitative analysis results model

\section{Discussion}

The qualitative findings show a generally positive reception to the NEC contract. In the experience of those interviewed, the impetus to good project management provided by the contract comes at the expense of more onerous contract administration. This requires additional contract management resourcing compared to other forms of contract, as suggested might be the case by Gould (2015). A clear lack of understanding of the contract and its procedures is demonstrated by a sector of the industry who do not operate the contract as it is intended, leading potentially to contract failure and dispute (Klein, 2015; Doherty, 2012; and EC Harris, 2013). The interviewees unanimously view the requirement to act in a spirit of trust and mutual cooperation with cynicism, particularly due to the economic conditions prevalent in the construction industry in the wake of the recent economic recession. 
Competition has increased fiercely due to the recent recession: all of the interviewees' organisations have suffered cuts to income and a corresponding drop in the level of resourcing available to manage the remaining project workload. This has forced contractors and consultants to 'cut corners' in terms of project administration and training. Some contractors are resorting to opportunism and will exploit any available chance to maximise their income on a particular project as a survival tactic.

From the key qualitative findings, a model of the forces exerted by the introduction of the NEC contract and the recent economic recession is developed:

Figure 3. Model of the forces exerted on the operation of the NEC contract

In the experience of those interviewed, two counteracting forces have frustrated the operation of the contract. The NEC contract's introduction in Northern Ireland has increased the requirement for training, project resourcing and requires the parties to act in a spirit of trust and mutual cooperation. However, the recent economic recession has exerted opposing forces on the interviewees and their organisations. Income and project resourcing has been reduced, introducing conditions where opportunism and game playing are rife (as also found by Williamson, 1975.) Business vulnerability and the economic fight for survival as described by the interviewees and Rousseau et al. (1998,) and Khalfan et al. (2007) increases adversarial behaviour and decreases trust, acting against the contractual requirement for trust and cooperation.

Whilst the quantitative analysis broadly confirms the results of the qualitative analysis, the greater number of quantitative responses allows a more nuanced picture of the experiences of 
different categories of respondent of the NEC contract under difficult economic conditions to be built up (Abowitz and Toole, 2010).

The study establishes that the majority of respondents find early warning and compensation events to be beneficial and outlines that the NEC contract does stimulate good project management. The first factor from the data reduction process describes a positive reaction to the contract, with a belief in the need for a contract like the NEC. This is an affirmation amongst those surveyed that they find the contract and its provisions to be useful, flexible and fair. This positive reaction is reflected in the continued uptake of the contract, particularly for large, complex projects (Gould, 2015).

Conversely, the more experienced survey respondents are less likely to welcome the introduction of the NEC contract and feel that experienced, competent project teams would succeed regardless of the contract. To some extent this is true, that project success is due as much to the project 'chemistry' (Nicollini, 2002) of the personalities involved than the form of contract (Khalfan et al., 2007; Thompson et al., 2000). This also may reflect a reluctance to relinquish the experiential advantage over less experienced colleagues built up using other forms of contract - the less experienced respondents may focus on evidence which confirms their preconceived perceptions of the contract when evaluating its usefulness (Soyer and Hogarth, 2015). Tushman and O Reilly (1996) describe the process of innovation as one which breaks up existing power relationships. In the case of NEC adoption, this process may disadvantage those who have built up a position based on knowledge of other contracts types.

Those working in larger organisations are less likely to have used the contract before, whilst believing that contractors have the necessary skills to operate the contract, and that use of the contract is likely to lead to fewer disputes. Only $28 \%$ of all respondents agree that their 
knowledge of the contract is comprehensive and thorough, although this proportion increases amongst those who have used the contract before. This suggests that theoretical knowledge of the contract is best consolidated through the practical experience of operating it. As use of the contract becomes more widespread, industry knowledge of its use will become further embedded (Gould, 2015), and its procedures will be followed more strictly (Eggleston, 1996).

The impact of the 2007 / 2008 recession is still being felt in the Northern Ireland construction industry. The vast majority of those interviewed or who responded to the questionnaire report a drop in income or profit from their 2007 / 2008 level. Design Consultants’ perception of their level of income relative to before the recession is much worse than that of Contractors. The qualitative research finds that design fees in some sectors (for example, education) are historically low. The quantitative analysis has found that since the onset of the recession, contractors are more likely to do whatever they can, within the bounds of the contract, to gain additional income for their organisation than Design Consultants. This confirms the findings Khalfan et al. (2007) and Manu et al. (2012) that opportunism tends to increase and trust to decrease in times of economic difficulty. This endorses Latham's premise that a scarcity of resources will in turn reduce trust. Williamson (1975) and Cousins et al. (2008) also predict that opportunism increases in economically difficult conditions. Under the NEC contract there is more scope for contractors than design consultants to gain additional income, and consultants are obliged by the NEC to assess contractors' claims within specific timeframes, otherwise they are deemed to be accepted (Ennis, 2010). Design Consultants feel more strongly than Contractors that opportunism and game playing has increased since the start of the recession. This opportunism and game playing, combined with more frequent compensation event claims, creates additional work for the Consultants for little additional gain. 
Interviewees report that as businesses are fighting for survival, some clients (including those in the public sector) have exacerbated cash flow problems by making late payments - many despite a legal commitment to prompt payment. The survey respondents overwhelmingly agree that late payment does impact trust and mutual cooperation, which is a key element in the optimal operation of the NEC contract.

\section{Conclusions}

The onset of the 2007 recession had been predicted by few economists, hence the Northern Irish Central Procurement Directorate cannot be faulted for their decision to introduce a relatively new form of contract, the NEC3, as their contract of choice in 2006. Unfortunately, this decision was shortly followed by the worst recession in living memory - the construction sector being one of the first areas of the economy to be affected and appears to be one of the last sectors to emerge from the poor economic conditions. However, recent output and productivity data have shown promising signs of recovery.

This research fills the identified gap in research between studies focusing purely on the NEC contract and its implementation, and on those solely examining the impact of the economic downturn. It explores the early years of NEC contract implementation in Northern Ireland and the impact of the recession on the ability of project participants to train for, understand, resource and operate it. The research aim is to test the hypothesis which consists of three elements. First, that trust is fragile and difficult to build and cannot be created through a clause in a contract. Second, that economic contraction has decreased available resources and increased the vulnerability of organisations. Third, that opportunism and game playing has increased during the recession. Finally, these elements are combined: the decrease in trust 
and cooperation and decrease in available resource has negatively impacted the operation of the NEC contract.

The first section of the hypothesis is confirmed through both the quantitative and qualitative research. The interviewees report a reduction in trust due to the recession and are unanimously scornful of the idealistic contract clause which exhorts a spirit of trust and cooperation. The raw questionnaire results confirm that, on average, the respondents believe that trust within project teams has been reduced and that use of the NEC contract will not lead to an increase in trust and cooperation between project participants.

The second section of the hypothesis is also confirmed through both qualitative and quantitative research. Analysis of the interviews and questionnaire indicates that income levels, fees and resourcing have been reduced across the industry, as a result of increased competition for less work during the study period. Further exacerbating the problems encountered by some consultants is their lack of NEC3 contract knowledge reported in the qualitative analysis. This problem is dissipating as economic conditions improve and more people in the construction industry gain experience and knowledge of the contract.

The study has found that game playing and opportunism has increased due to the recession during the study period. This third part of the hypothesis has been confirmed through the qualitative and quantitative analysis. Through sample t test comparison, consultants report a greater decline in income than contractors, potentially because contractors have greater scope within the NEC contract for additional claims. This may be because contractors are more likely to exploit claims, doing whatever they have to within the bounds of the contract to maximise their income from a project. This increase in opportunism has further stretched consultants' income, as they cannot claim additional fees from a client simply for dealing 
with numerous claims from the contractor. This bears out the views held by Latham (1994) Williamson (1975) and Cousins et al. (2008) that opportunism flourishes when competition is high and resources are low. Contractors' aggressive maximisation of their profit is hardly conducive to the spirit of trust and mutual cooperation called for by the contract, although the pressure to squeeze any potential financial gain from contracts is dissipating with time as economic conditions improve.

Through confirmation of the three sections of the hypothesis above, we can confirm that the recession has decreased trust and cooperation, and decreased available project resource, negatively impacting the operation of the NEC contract.

Evaluation of the effectiveness of the NEC contract using project outcomes has been lacking during the recession. The post-recession construction industry is in a fluid and dynamic situation, where economic conditions remain unpredictable. Due to the time bound and geographically limited nature of this study, the results represent a limited period of time in a specific location. Economic conditions have improved a little since this study was completed. However, contractors' and consultants' income is still under pressure and the threat of recession persists. The critical realist stance adopted does limit the generalisability of the study to its particular social context. However as mentioned elsewhere in the text, the NEC contract has been used extensively across the world, and the problems generated for the construction industry by the recession were felt worldwide. Therefore, the results will be of interest to an international audience. It would, however, be beneficial to study the effect of the recession on the industry, particularly with respect to its impact on the operation of the NEC contract, using project outcomes and economic data, over a longer period of time and across a wider geographical area. 
This study provides academia with a deeper understanding of the interplay of the effects of the recession on the operation of the NEC contract, and gives an insight into the pressures which contractors and consultants have been operating under during and in the aftermath of the recent recession. In addition, the critical realist stance adopted demands that practical recommendations for industry be generated. An appreciation of the effects of the recent economic recession on the impact of the contract will benefit those who are planning construction works and making decisions on contract use and project resourcing. As a result of these findings, it is recommended that clients should ensure on appointment that all project participants are adequately resourced to fulfil the terms of their respective contracts. From a client's perspective, this should apply particularly to consultants, who will be looking after the clients' financial interests. Regarding contractors and consultants, it is recommended that projects using the NEC contract be given adequate contract administration resourcing. This should ensure that the contract provisions are followed correctly, and that sufficient economic 'space' is given to create the conditions where trusting relationships and cooperation can develop.

\section{References}

Abowitz, D.A. and Toole, T.M. (2010) Mixed method research: Fundamental issues of design, validity, and reliability in construction research. Journal of Construction Engineering and Management, 136 (1) 108 - 118

Acton, C. and Miller, R. (2009) SPSS for social scientists, Palgrave Macmillan, London.

Ankrah, N.A. and Langford, D.A. (2005) Architects and contractors: a comparative study of organizational cultures. Construction Management and Economics, 23, 595-607

Bhaskar, R. (2008) A realist theory of social science. Routledge, London 
Bennet, F., Fergusson, W. and Palmer, M. (2009) New Zealand Meridian Energy and the NEC Four Years of Experience In: 11th Annual Contract Performance Management Summit Construction \& Infrastructure Contract Masterclass Auckland, February 2009.

Bingham, T. (2012) The bad side of good faith clauses. Building April 2012.

Bingham, T. (2013) Recognising the principle of good faith. Building March 2013.

Bresnen, M. and Marshall, N. (1998) Partnering strategies and organizational cultures in the construction industry. In: Hughes, W. (Ed.) Proceedings of the 14th Annual ARCOM Conference, 9-11 September 1998, Reading, UK, Association of Researchers in Construction Management, 465-76.

Brooks, T., and Spillane, J. P. (2015) The impact of the recent economic recession on the NEC contract in Northern Ireland: A preliminary study In: Raidén, A B and Aboagye-Nimo, E (Eds) Procs $31^{\text {st }}$ Annual ARCOM Conference, 7-9 September 2015, Lincoln, UK, Association of Researchers in Construction Management, 1219-1228.

Broome, J. (1997) Best practice with the New Engineering Contract. Proceedings of the Institute of Civil Engineers Issue 120, 74-81.

Broome, J., and Hayes, R. (1997) A comparison of the clarity of traditional construction contracts and of the New Engineering Contract. International Journal of Project Management 15(4) 255261.

Buchanan, J. (2001) Game theory, mathematics, and economics. Journal of Economic Methodology 8(1), 27-32.

Challendar, J., Farrell, P., and Sherrat, F. (2014) Partnering in practice: an analysis of collaboration and trust. Proceedings of the Institution of Civil Engineers Management, Procurement and Law 167(6), 255-264.

Cousins, P., Lamming, R., Lawson, B., and Squire, B., (2008) Strategic Supply Management Pearson Education. London. 
Cresswell, J.W. (2003) Research Design (2nd Ed) Sage, Thousand Oaks California.

Dainty, A. (2007) A call for methodological pluralism in built environment research. In Proceedings of the Third Scottish Conference for Postgraduate Researchers of the Built and Natural Environment, Glasgow Caledonian University, November 20 - 22, 1-10

Dancaster, C. (2008) Construction adjudication in the United Kingdom: Past, present, and future. Journal of Professional Issues in Engineering Education and Practice 134(2) 204-208.

Denzin, N. K. (1978) The Research Act, 2nd Ed, McGraw Hill, USA

DFPNI (Department of Finance and Personnel Northern Ireland), (2014) Northern Ireland Construction Bulletin Output in the Construction Industry - Q1 2014, DFPNI / Northern Ireland Statistics and Research Agency, Belfast.

Doherty, M., (2012) When NEC Contracts fail, Quigg Golden Insight, Belfast.

Eadie, R., McKeown, C., and Anderson, K. (2013) The impact of recession on construction procurement routes. International Journal of Procurement Management, 6(1), 25-38.

EC Harris, (2013) Use NEC contracts with caution, warns EC Harris. Construction Manager May 2013

Eggleston, B (2006) The NEC 3 engineering and construction contract. Blackwell, Oxford, UK.

Ennis, C. (2010) Financial claims under NEC contracts: an overview Society of Construction Law annual conference, March 2010, Leeds Society of Construction Law, 1 - 20.

Field, A. (2009). Discovering statistics using SPSS, 3rd Ed., Sage, London.

Gerrard, R. (2005) Relational Contracts in perspective, Lean Construction Journal 2 (1) 80 - 86

Gould, N., (2015) NEC Contracts: Programming, Project Management and Pricing - have they stood the test of time, Annual Update of the Centre of Construction Law \& Dispute Resolution, September 2014, King's College London, Society of Construction Law, . 1-46. 
Guba, E., \& Lincoln,Y. (2005). Paradigmatic controversies, contradictions, and emerging confluences. In N. Denzin \& Y. Lincoln (Eds.), Handbook of qualitative research (3rd ed., 191-215). Thousand Oaks, CA: Sage.

Hall, R.E., (2011) The long slump American Economic Review 101, April 2011, 431-469.

Howe, K. R. (1988). Against the quantitative-qualitative incompatability thesis, or, Dogmas die hard. Educational Researcher, 17, 10-16.

Hughes, W., and Maeda, Y. (2002) Construction contract policy: do we mean what we say? RICS Research Papers, 4(12), 1-25.

Johnson, R. B., Onwuegbuzie, A. J., \& Turner, L. A. (2007). Toward a definition of mixed methods research. Journal of mixed methods research,1(2), 112-133.

Kang, J. (2006) Strategic analysis of large local construction companies in China, Singapore: PhD thesis, Nanyang Technological University.

Kadefors, A., (2004) Trust in project relationships—inside the black box. International Journal of Project Management, 22, 175-182.

Khalfan, M., McDermott, P., and Swan, W. (2007) Building Trust in construction projects. Supply Chain Management, 12(6), 385-391.

Klein, R. (2015) Revisiting the curse of the Z clause. NEC User's Group Newsletter, 75, 3

Krugman, P (2009) How did economists get it so wrong? New York Times Magazine Sept 2, 2009

Kuhn, T. (1996). The structure of scientific revolutions (3rd ed). Chicago: University of Chicago Press.

Kumar, R. (2005) Research methodology: A step-by-step guide for beginners, SAGE, London.

Latham, M. (1994) Constructing the Team, Final report of the government/industry review of procurement and contractual arrangements in the United Kingdom construction industry, HMSO, Department of Environment, London. 
Lipscomb, M. (2011). Critical realism and realist pragmatism in mixed methods: Problematics of event identity and abductive inference. Professors of Education Research Symposium: Evolving Paradigms in Mixed Methods Research. American Education Research Association, New Orleans, LA

Loosemore, M. (1988) The three ironies of crisis management in construction projects. International Journal of Project Management, 16(3), 139-144.

Lowe, J. G., and Moroke, E. (2010) Insolvency in the UK construction sector. In: ed. C. Egbu, Proceedings of the 26th Annual ARCOM Conference, 6-8 September 2010. Leeds Association of Researchers in Construction Management, 93-100.

Manu, E., Ankrah, N. A., Chinyio, E. and Proverbs, D. G. (2012) Influence of the macroeconomy on trust in construction supply chains. In: ed S Smith, Proceedings of the 28th Annual ARCOM Conference. Edinburgh, Association of Researchers in Construction Management, 665-674.

Mason, J. (2008) Delivering improvements in ethical behaviour in the construction industry through the implementation of contractual good faith provisions. In: P. Fewings, ed. Ethics for the Built Environment. Bristol: Taylor and Francis, 3-10.

Maxwell, J. A., \& Mittapalli, K. (2010). Realism as a stance for mixed method research. In A. Tashakkori \& C. Teddlie (Eds.), Handbook of mixed methods in social \& behavioral research, (2nd ed.,). Thousand Oaks, CA: Sa, 145 - 168

Mayer, R.C., Davis, J.H., and Schoorman, F.D. (1995) An integrated model of organizational trust. Academy of Management Review 20, 709-39.

McCloskey, J. (2012) Public Procurement Challenges in Northern Ireland. A paper presented to the Society of Construction Law, October 2012, Belfast, Society of Construction Law, pp. 1 - 25.

Meng, X. (2014) Is Early Warning Effective for the Improvement of Problem Solving and Project Performance? Journal of Management in Engineering, 30(2), 146-152

Minogue, A. (2013) Leap of faith, Building April 2013 
Morgan, D. L. (2007) Paradigms lost and pragmatism regained methodological implications of combining qualitative and quantitative methods. Journal of mixed methods research, 1(1), 4876.

Nicolini, D. (2002) In search of 'project chemistry'. Construction Management and Economics, 20, 167-177.

Oyedele, L. O., and Tham, K. W. (2007) Clients' assessment of architects' performance in building delivery process: Evidence from Nigeria. Building and Environment 42(5), 2090-2099

Pinto, J. K., Slevin, D. P. and English, B. (2008) Trust in projects: An empirical assessment of owner/contractor relationships. International Journal of Project Management, 27, 638-648.

Porter, M. E. (1980) Competitive Strategy - Techniques for Analysing Industries and Competitors. New York: The Free Press.

Rooke, J. and Seymour, D. (1995) The NEC and the culture of the industry: some early findings regarding possible sources of resistance to change. Engineering, 2(4), 287-307.

Rousseau, D. M., Rousseau, S. B. and Camerer, C. (1998) Not so different after all: A cross-discipline view of trust. Academy of Management Review 23, 393- 404.

Simon, H. A. (1972) Theories of Bounded Rationality. In: C. M. a. R. Redner, (ed.) Decision and Organisation. New York: American Elsevier Publishing Company, 161 - 176.

Smyth, H., Gustafsson, M. and Ganskau, E. (2010) The value of trust in project business. International Journal of Project Management, 28, 117-129.

Soyer, E. and Hogarth, R.M. (2015) Fooled by Experience Harvard Business Review May 201573 77.

Stimpson, J. (2011) Success or failure of an NEC contract is all in the mindset. New Civil Engineer February 2011

Stock, James H., and Mark W. Watson. Disentangling the Channels of the 2007-2009 Recession. No. w18094. National Bureau of Economic Research, 2012. 
Strauss, A. and Corbin, J. (1998) Basics of qualitative research: Techniques and procedures for developing grounded theory. 2nd ed. Thousand Oaks, CA: Sage.

Subbiah, A. (2012) An investigation of the factors influencing the success of construction planning for the 2012 Olympic stadium: An ethnographic study In: Smith, S.D (Ed) Procs 28th Annual ARCOM Conference, 3-5 September 2012, Edinburgh, UK, Association of Researchers in Construction Management, 1035-1045.

Tang, L. and Koveos, P. (2008) A framework to update Hofstede’s cultural value indices: economic dynamics and institutional stability. Journal of International Business Studies, 39(1), 10451063.

Tansey, P., Meng, X. and Cleland, D. (2013) A critical review of response strategies adopted by construction companies during an economic recession. In: S. Smith, ed, Proceedings of the 29th Annual ARCOM Conference, 2-4 September. Reading: Association of Researchers in Construction Management, 679 - 689.

Tansey, P. and Spillane, J. P. (2014) Government influence on the construction industry during the economic recession 2007 - 2013 In: Raiden, A B and Aboagye-Nimo, E (Eds) Procs 30 ${ }^{\text {th }}$ Annual ARCOM Conference, 1-3 September 2014, Portsmouth, Association of Researchers in Construction Management, 1101-1110

Tansey, P., Spillane, J, \& Meng, X. (2014) Linking response strategies adopted by construction firms during the 2007 economic recession to Porter’s generic strategies, Construction Management and Economics, 32:7-8, 705-724

Tashakkori, A. and Teddlie, C. (2003). Major issues and controversies in the use of mixed methods in the social and behavioral sciences. In A. Tashakorri \& C. Teddlie (Eds.), Handbook of mixed methods in social \& behavioral research. Thousand Oaks, CA: Sage. 3-50Thompson, R.M., Vorster, M.C and Groton, J.P. (2000) Innovations to Manage Disputes: DRB and NEC. Journal of Management in Engineering, 16 (5), 51-59. 
Tushman, M. L. and O Reilly, C. A. I. (1996) Ambidextrous Organisations: Managing Evolutionary and Revolutionary Change. California Management Review, 38(4), 8-30.

Verick, S. and Islam, I. (2010) The great recession of 2008-2009: causes, consequences and policy responses. Forschungsinstitut zur Zukunft der Arbeit, No 4934

Williamson, O. (1975) Markets and Hierarchies: Analysis and Antitrust Implications. New York: Free Press.

Zeng, S.X., Chen, H.M. and Tam, C.M. (2005) Market structure of the construction industry of China. Architectural Science Review, 48(4), 367-75. 